\section{Electropolymerized Congo Red Film based Sensor for Dopamine: A Voltammetric Study}

\section{Abstract}

The polymerization film of Congo red was prepared on the surface of carbon paste electrode by electropolymerization using cyclic voltammetric method. The higher catalytic activity was obtained for electrocatalytic oxidation of Dopamine, with drastic enhancement of the reversibility and peak current in 0.2 phosphate buffer solution of $\mathrm{pH} 7.0$ at the sweep rate $100 \mathrm{mV} / \mathrm{s}$. The variation of sweep rate and $\mathrm{pH}$ were investigated. The limit of detection of Dopamine was found to be 0.06 $\mu \mathrm{M}$. The effect of interference studies was done by differential pulse voltammetric technique. In the simultaneous look at, Dopamine and Uric acid were well separated by cyclic voltammetric technique. The proposed method showed good sensitivity, selectivity, and reproducibility.

Keywords: Dopamine; Uric acid; Congo red; Cyclic voltammetry; Electropolymerization; Carbon paste electrode

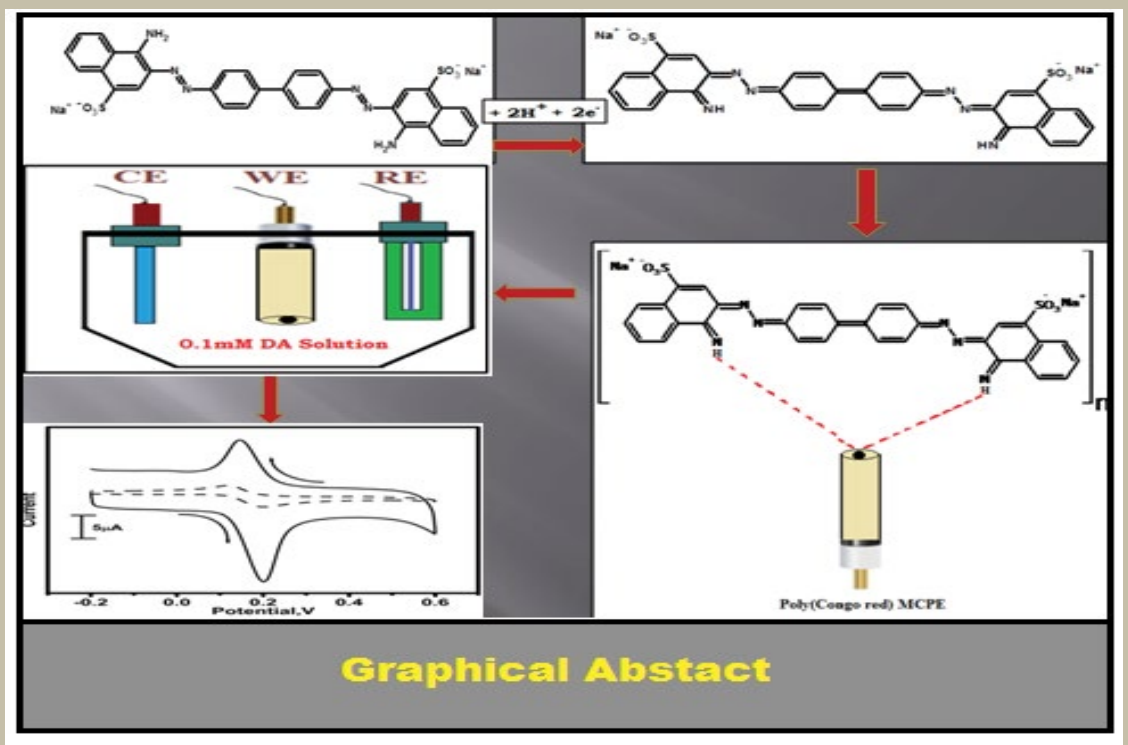

Chethan M Kuskurr ${ }^{1}$, Kumara Swamy $\mathrm{BE}^{1 *}$, Jayadevappa $\mathrm{H}^{2}$ and Shivakumar $\mathrm{K}^{3}$

\section{Department of PG Studies and} Research in Industrial Chemistry, Kuvempu University, Jnana Sahyadri, Shankaraghatta, Shimoga, Karnataka, India

2 Departments of Chemistry, Sahyadri Science College, Shimoga, Karnataka, India

3 Departments of Chemistry, PES Institute of Technology and Management, Shimoga, Karnataka, India

\section{Corresponding author:}

Kumara Swamy BE

\section{”kumaraswamy21@yahoo.com}

Department of PG Studies and Research in Industrial Chemistry, Kuvempu University, Jnana Sahyadri, Shankaraghatta, Shimoga, Karnataka, India.

Tel: +918282256225

Fax: +918282256255

Citation: Kuskur CM, Kumara Swamy BE, Jayadevappa H, Shivakumar K. Electropolymerized Congo Red Film based Sensor for Dopamine: A Voltammetric Study. Insights Anal Electrochem. 2017, 3:1.

\section{Introduction}

Dopamine, which belongs to the catecholamine family of neurotransmitters, is synthesized in a sequential reaction in which tyrosine hydroxylase and amino acid decarboxylase convert tyrosine to L-dihydroxyphenylalanine (L-dopa), followed by decarboxylation of L-dopa to dopamine. Dopamine plays a vital role in the control of movements and has been associated with the motor symptoms experienced in patients with
Parkinson's disease [1]. Other studies show that the dopamine oxidation products can inhibit the function of specific proteins [2] and correlate formation of cysteine I-dopamine conjugates with dopamine-induced neurotoxicity. As a potent neurotransmitter, changes in the level of dopamine in adrenal glands impact many aspects of brain circuitry. For example, Parkinsonism is associated with a reduced level of dopamine; while schizophrenia is related to increased dopamine activity [3]. 
In vivo concentrations of dopamine are in the nanomolar range. Given the wide range of physiological and path physiological implications, the development of analytical assays for precise, low level, and selective measurement of dopamine are highly desirable [4]. DA is produced by substantial nigra neurons and found in large quantities $(50 \mathrm{~m} \mathrm{~mol} / \mathrm{g}$ ) in the caudate nucleus, a region of the brain $[5,6]$. In the human body, DA is typically broken down by the oxidation that is catalyzed by enzyme monoamine oxidase. Conversely, DA is also able to undergo autoxidation i.e., it reacts with oxygen, yielding free radicals along with quinones as products $[7,8]$. Hence, it is essential to develop a simple and rapid quantification method for DA in routine analysis for diagnostic, neurological and pharmaceutical applications.

On the other hand, Uric acid is the primary end product of purine metabolism in the human body [9]. In a healthy human being, the typical concentration of UA in urine is around $2 \mathrm{mM}$ and in the blood, is in between $120 \mu \mathrm{M}$ to $450 \mu \mathrm{M}$ ranges [10,11]. Extreme abnormalities of UA levels are Symptomic of several diseases, such as cardiovascular disease [12], hyperuricemia, uric acid stones [13], gout and Le-seh-Nyhan syndrome [14]. Increased rate level also leads to pneumonia and leukaemia $[15,16]$. Dopamine and uric acids usually coexist in physiological samples, dopamine normally present at low concentration along with uric acid which is at higher concentration. The simultaneous determination of these compounds is a special interest in the development of electrochemical sensors [17]. The successful route to overcome the problems of selectivity is to modify the carbon paste electrode surface because the modified electrode could decrease the over voltage, improve the velocity of mass transfer efficiency and enhances the selectivity of the analyte [18]. The modification can be done by using organic and inorganic substances and biomolecules [19-21]. In the present day's electropolymerization technique was used to prepare the polymer-modified electrodes have received wide interest in the detection of analytes because of its high selectivity, and homogeneity in electrochemical deposition, strong adherence to the electrode surface and chemical stability of the films [22-24]. Shahrokhian et al. [25] has reported the Synthesis of Polypyrrole in the Presence of Congo Red; Application to Selective Voltammetric Determination of Dopamine in the Presence of Ascorbic Acid. Until now, different methodologies have been used to prepare polymeric film modified electrodes. Among them, electropolymerization yields a modified electrode with a three-dimensional distribution of mediators. This type of electrodes enhances the sensitivity and improves the catalytic activity than monolayers and few reports have been reported [26-29]. Congo red is the sodium salt of 3,3'-([1,1'-biphenyl]-4,4'-diyl) bis (4-aminonaphthalene-1sulfonic acid) is an azoic compound synthesized by Paul Böttiger is used to stain microscopic prepares, especially as a cytoplasm and erythrocyte stain (Scheme 1) [30].

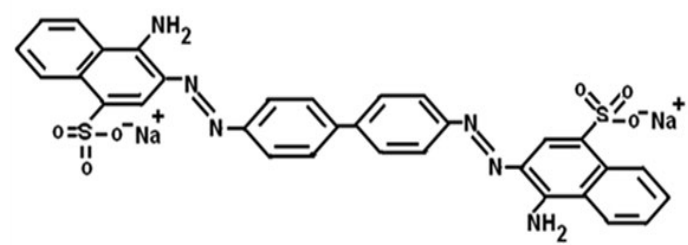

Scheme 1 Structure of Congo red.
In this study, the modification of stable working electrode by electro polymerizing Congo red on the bare carbon paste electrode surface by CV method and used for the voltammetric determination of DA and UA. The poly (Congo red) MCPE shows very good enhancement when compared to BCPE and also it shows good sensitivity, selectivity, and stability for the determination of the two neurotransmitters like DA and UA.

\section{Materials and Methods}

Cyclic voltammetric experiments were performed on a model $\mathrm{CH} 660 \mathrm{c}$ ( $\mathrm{CH}$ instrument). All the electrochemical experiments were carried out in a three-electrode cell system, which contained a bare carbon paste electrode (BCPE)/ Poly (Congo red) film coated MCPE as the working electrode, a platinum wire and saturated calomel electrode as counter and reference electrode.

\section{Reagents and chemicals}

Graphite powder of $50 \mathrm{~mm}$ size was purchased from Loba and silicon oil was purchased from Himedia. Congo red, Dopamine hydrochloride (DA) and Uric acid (UA) were obtained from Himedia. All the chemicals are of analytical grade quality and were used as supplied without further purification. $25 \times 10^{-4} \mathrm{M}$ Congo red was prepared in double distilled water, $25 \times 10^{-4} \mathrm{M}$ DA was prepared in $0.1 \mathrm{M}$ Perchloric acid $\left(\mathrm{HClO}_{4}\right), 25 \times 10^{-4} \mathrm{M}$ UA was prepared in $0.1 \mathrm{M}$ sodium hydroxide, and Phosphate buffer solution (PBS) of same ionic strength was prepared $(0.2$ $\mathrm{M})$ by mixing appropriate ratio of sodium dihydrogen phosphate $\left(\mathrm{NaH}_{2} \mathrm{PO}_{4} \cdot \mathrm{H}_{2} \mathrm{O}\right)$ disodium hydrogen phosphate $\left(\mathrm{Na}_{2} \mathrm{HPO}_{4}\right)$.

\section{Preparation of bare carbon paste electrode}

Bare carbon paste electrodes (BCPE) were made with silicon oil $(30 \%)$, and graphite powder (70\%). The two components were thoroughly mixed in an agate mortar for about 30 minutes. The BCPE was packed into a homemade Teflon cavity having a current collector and was polished on a weighing paper.

\section{Results and Discussion}

\section{Electropolymerization of poly (Congo red) MCPE at CPE surface}

The modified carbon paste electrode was fabricated by electrochemical polymerization process over the potential range from -0.2 to $1.5 \mathrm{~V}$ at a sweep rate of $100 \mathrm{mV} / \mathrm{s}$ for 20 cycles. The poly (Congo red) modified carbon paste electrode (MCPE) was prepared by placing $1 \mathrm{mM}$ Congo red with $0.1 \mathrm{M} \mathrm{NaOH}$ in an electrochemical cell. Figure 1 suggests that during first cycle a small anodic peak was observed corresponding to the oxidation of Congo red monomer [31]. During the polymerized process, with increasing the number of cyclic time corresponding voltammogram was slowly decreased. It shows that the poly (Congo red) film was produced and deposited at the surface of $\mathrm{BCPE}$. Once electropolymerization process complete; the MCPE was rinsed carefully with double distilled water.

\section{Effect of different cycles of poly (Congo red) MCPE}

From the above experimental result shows, the thickness of the 
film has a major role on the electrocatalytic property of the poly (Congo red) MCPE. The formation of the layer can be adjusted by controlling the cyclic number of voltammetric scans on the BCPE (from 5 to 30) and corresponding anodic peak current at $0.1 \mathrm{mM}$ DA in presence $0.2 \mathrm{M} \mathrm{PBS}$ of $\mathrm{pH}$ 7.0. The graphs of anodic peak current of DA versus number of cycles were plotted as shown in Figure 2. However, by considering the peak nature of the cyclic voltammogram the increment in the anodic peak current, the twenty cycles polymerized MCPE was optimized for the further electrochemical analysis. The probable mechanism of formation of the polymer film as reported in the literature [30].

\section{Voltammetric behaviour of DA at Poly (Congo red) MCPE}

Figure 3 showed the CV recorded for the oxidation $0.1 \mathrm{mM}$ DA at BCPE (dashed line) and Poly (Congo red) MCPE (solid line) in $\mathrm{pH} 7.0$ of $0.2 \mathrm{M}$ PBS with the sweep rate $100 \mathrm{mV} / \mathrm{s}$. In BCPE, the oxidation and reduction of DA were less sensible due slow electron transfer and the peak potentials were observed at 202 and $116 \mathrm{mV}$ respectively. [ $\triangle \mathrm{Ep}=96 \mathrm{mV}$ ]. Under the same condition at poly (Congo red) MCPE shows significantly enhanced in the redox peak current, the oxidation and reduction peak potentials were observed at 202 and $146 \mathrm{mV}$ [ $\Delta \mathrm{Ep}=56]$. It above result shows, the oxidation peak of dopamine was enhanced at MCPE, because of formation of high concentration of negatively charged $-\mathrm{SO}_{3}$ - group and electron rich oxygen atom on the surface of the electrode at neutral $\mathrm{pH}$. These electron rich groups result in that the poly (Congo red) MCPE shows a good affinity towards the DA positive ions by exchanging the electrons and enhanced the oxidation of DA [25,30,32].

\section{Effect of sweep rate}

The Figure 4a shows the effect of applied sweep rate for the oxidation of $0.1 \mathrm{mM}$ DA recorded at different sweep rates using poly (Congo red) MCPE in 0.2 M PBS of pH 7.0. From the above figure shows an increase in the redox peak current with increases the sweep rates from 50 to $400 \mathrm{mV} / \mathrm{s}$. To evaluate the electrode process, the graph of Ip versus sweep rates (u) was plotted (Figure $\mathbf{4 b}$ ). The obtained graph was the good linearity almost nearly straight line having a correlation coefficient value 0.9997 and 0.9989 respectively but in the same time the graph of Ip versus square root of sweep rates $\left(u^{1 / 2}\right)$ as shown in the Figure 4c, having correlation coefficient value 0.9880 and 0.9927 respectively. From the above scrutiny, overall electrode process was controlled by adsorption process at poly (Congo red) MCPE.

The heterogeneous rate constant $\left(k^{0}\right)$ values was determined from the experimental peak potential difference ( $\Delta E \mathrm{E})$ data's, Equation (1) was used for such voltammograms whose $\Delta \mathrm{Ep}$ values are greater than $10 \mathrm{mV}$ [33].

$\Delta \mathrm{Ep}=201.39 \log \left(\mathrm{u} / \mathrm{k}^{0}\right)-301.78$

From the experimental $\Delta E p$ values as shown in Table 1 and Equation (1); the values of the $k^{0}$ for the PA oxidation was determined. All the parameters are tabulated in Tables $\mathbf{1}$ and $\mathbf{2}$.

\section{Concentration effect of DA}

Figure $\mathbf{5 a}$ depicts cyclic voltammograms of poly (Congo red)
MCPE with different concentration from 0.1 to $0.5 \mathrm{mM}$ in $0.2 \mathrm{M}$ PBS of $\mathrm{pH} 7.0$ at the sweep rate $100 \mathrm{mV} / \mathrm{s}$. It can be seen that, redox peak current goes increase by increasing DA concentration. The graph of anodic peak current versus concentration of DA was
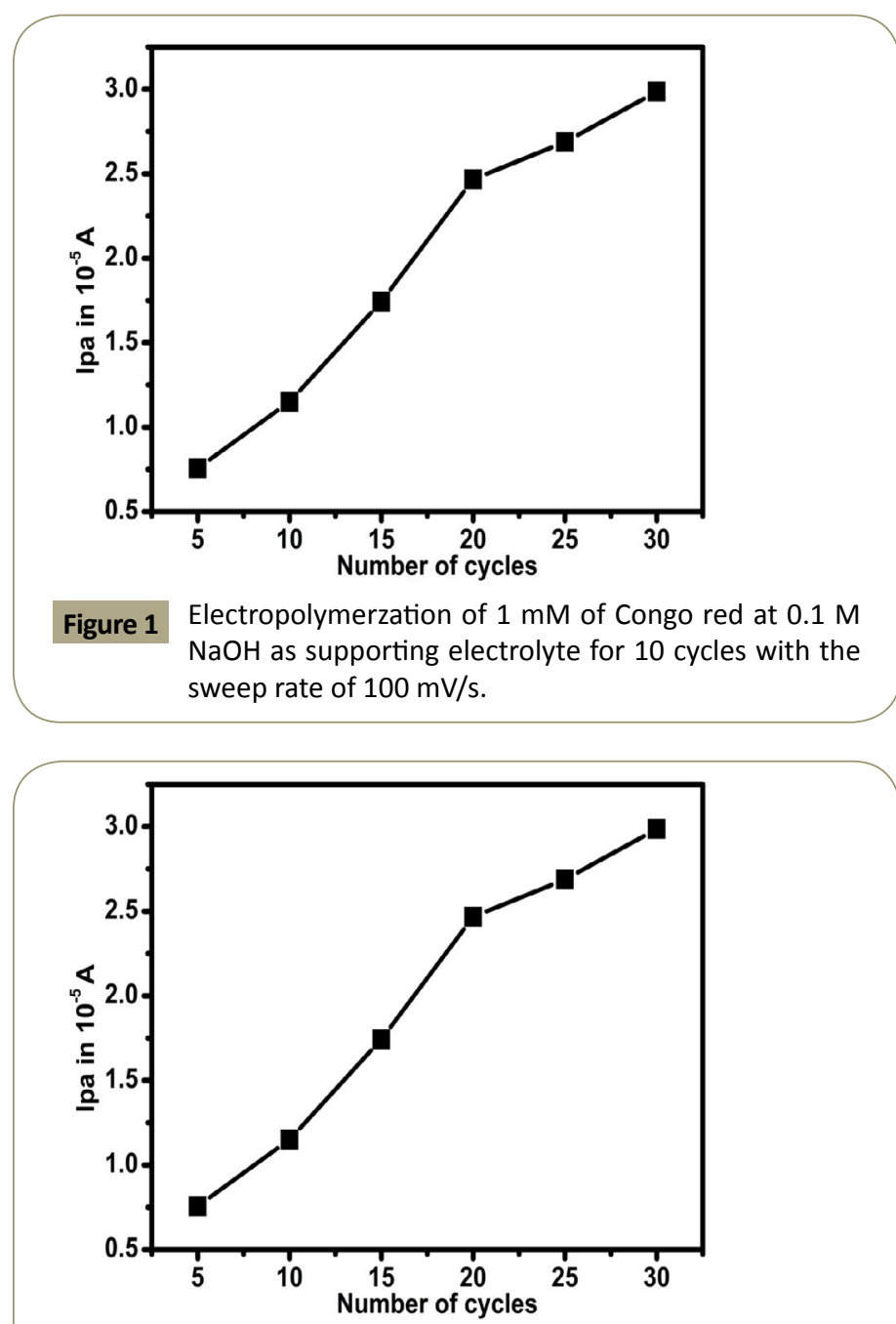

Figure 2 The graph of anodic peak current versus number of cycles.

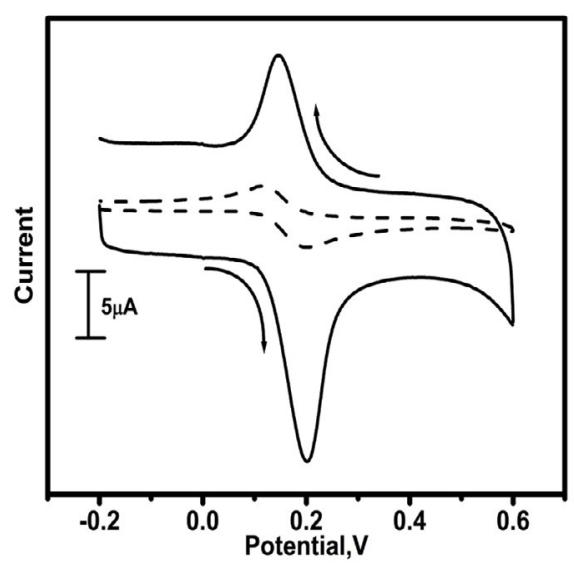

Figure 3 Cyclic voltammograms of $0.1 \mathrm{mM}$ DA in $0.2 \mathrm{M}$ PBS solution of $\mathrm{pH} 7.0$ at BCPE (dashed line) and poly (Congo red) MCPE (Solid line) at the sweep rate of 100 $\mathrm{mV} / \mathrm{s}$. 


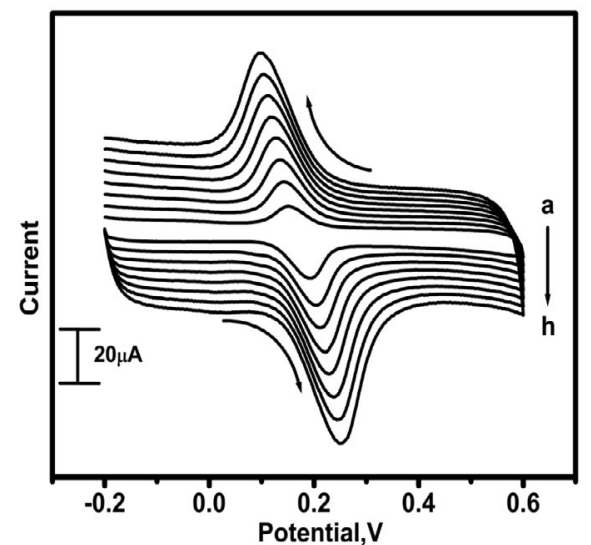

Figure 4a Cyclic voltammograms of $0.1 \mathrm{mM}$ DA in $0.2 \mathrm{M}$ PBS solution of $\mathrm{pH} 7.0$ at poly (Congo red) MCPE at different sweep rates (a-h; 50 to $400 \mathrm{mV} / \mathrm{s})$.

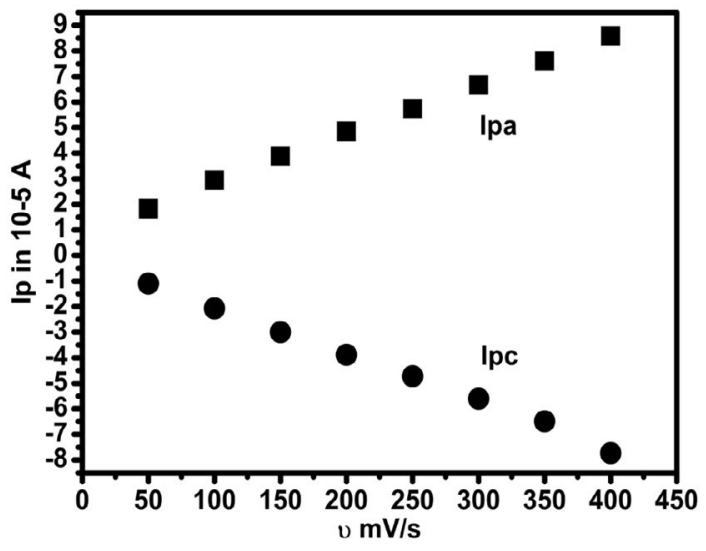

Figure $\mathbf{4 b}$ The graph of anodic peak current versus sweep rates.

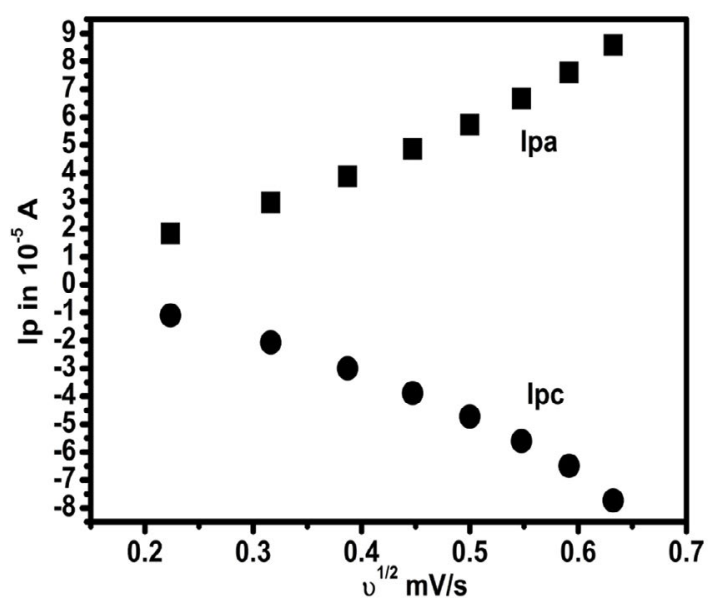

Figure 4C The graph of anodic peak current versus square root of sweep rates.

plotted and it was good linearity as shown in the Figure $\mathbf{5 b}$. The correlation coefficient $\left(r^{2}\right)$ was found to be 0.9933 . The limit of detection of the lower concentration range for DA was $0.06 \mu \mathrm{M}$ for the poly (Congo red) MCPE. The limit of detection (LOD) was

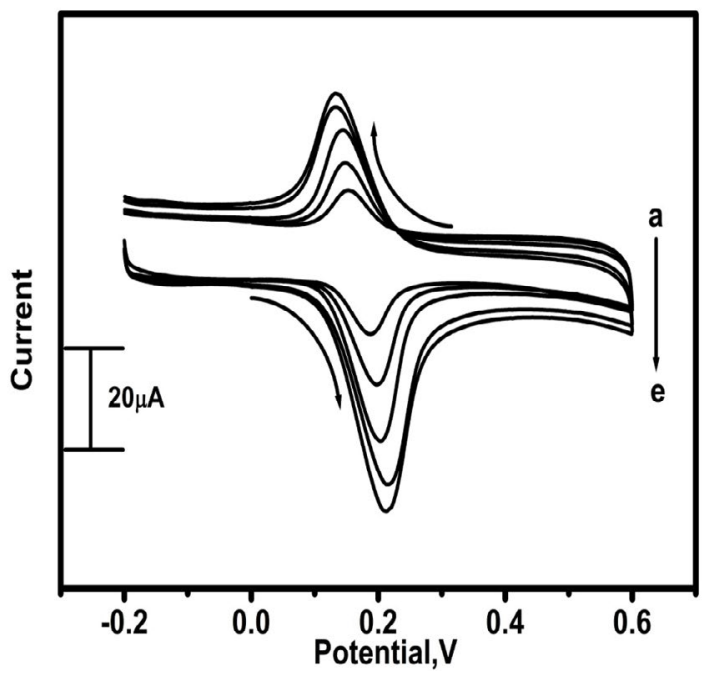

Figure 5a Cyclic voltammograms of DA in $0.2 \mathrm{M}$ PBS solution of $\mathrm{pH} 7.0$ at poly (Congo red) MCPE at sweep rate of 100 $\mathrm{mV} / \mathrm{s}$ with different concentrations (a-e:0.1 mM, 0.2 $\mathrm{mM}, 0.3 \mathrm{mM}, 0.4 \mathrm{mM}$ and $0.5 \mathrm{mM}$ ).

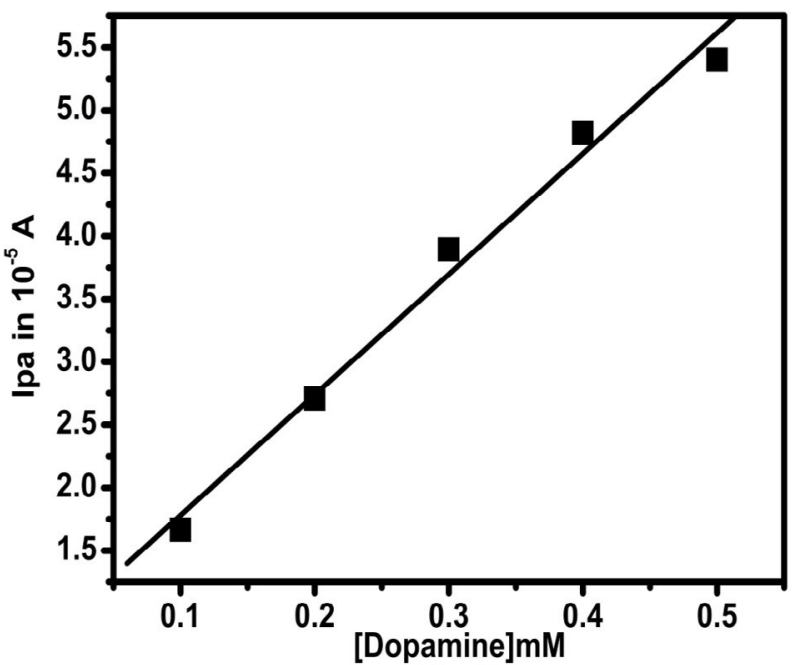

Figure 5b The graph of anodic peak current versus different concentration of DA.

Table 1 Electrochemical parameters of DA at different sweep rates.

\begin{tabular}{|ccc|}
\hline$u \mathrm{mV} / \mathrm{s}$ & $\Delta \mathrm{E}_{\mathrm{p}}(\mathrm{mV})$ & $\mathrm{k}^{0}\left(\mathrm{~s}^{-1}\right)$ \\
50 & 44 & 0.9574 \\
100 & 74 & 1.3614 \\
\hline 150 & 80 & 1.4996 \\
\hline 200 & 96 & 2.1134 \\
\hline 250 & 112 & 2.2029 \\
\hline 300 & 127 & 2.2284 \\
350 & 143 & 2.1627 \\
\hline 400 & 158 & 2.0844 \\
\hline
\end{tabular}

calculated by using with equation (2). Where $S$ is the standard deviation and $\mathrm{M}$ is the slope of obtained from the graph.

$\mathrm{LOD}=3 \mathrm{~S} / \mathrm{M}$ 
Table 2 Comparison of some modified electrodes for the determination of DA.

\begin{tabular}{|c|c|c|c|c|}
\hline S No & Electrode & Detection limit $(\mu \mathrm{M})$ & Techniques & Reference \\
\hline 1 & Banana/MWCNTs/MCPE & 2.09 & DPV & [35] \\
\hline 2 & Bicopper complex modified GCE & $1.4 \times 10^{-6}$ & DPV & [36] \\
\hline 3 & Self-assembled gold nanoparticle modified Gold electrode & $9.0 \times 10^{-5}$ & DPV & [37] \\
\hline 4 & Poly ( $p$-toluene sulfonic acid) modified glassy carbon electrode & $6.0 \times 10^{-7}$ & DPV & [38] \\
\hline 5 & Ionic liquid modified carbon paste electrode & $7.0 \times 10^{-7}$ & $\mathrm{CV}$ & [39] \\
\hline 6 & Poly (caffeic acid)/GCE & $2.0 \times 10^{-7}$ & CV & {$[40]$} \\
\hline 7 & Metallothioneins self-assembled gold electrode & $6.0 \times 10^{-6}$ & CV & {$[41]$} \\
\hline 8 & Poly (Congo red) MCPE & 0.06 & $\mathrm{CV}$ & In this work \\
\hline
\end{tabular}

\section{The effect pH on DA at Poly (Congo red) MCPE}

The supporting electrolyte of $\mathrm{pH}$ has a major role in the electrochemical behaviour of DA at poly (Congo red) MCPE. The Figure 6a depicts, cyclic voltammograms recorded in the solution containing $0.1 \mathrm{mM}$ DA. The graph of anodic peak potential versus different $\mathrm{pH}$ was plotted. The graph shows good linear relationship. The linear regression can be expressed by the equation: $E p a=0.061(\mathrm{pH})-0.633$, having correlation coefficient value 0.9969 , with the slope of $61 \mathrm{mV} / \mathrm{pH}$. This behaviour is nearly obeyed the Nernst Equation for a same number of proton and electron were involved in redox mechanism [34,42].

\section{Electrochemical determination of UA at Poly (Congo red) MCPE}

Figure 7 depicts electrochemical responses of $0.1 \mathrm{mM}$ UA at both BCPE (dashed line) and poly (Congo red) MCPE (Solid line) in 0.2 $\mathrm{M} \mathrm{PBS} \mathrm{pH} 7.0$ at the sweep rate $100 \mathrm{mV} / \mathrm{s}$. From the above result shows at BCPE, a small broad oxidation peak potential at 326 $\mathrm{mV}$ with less sensitivity and slow electron transfer kinetic. While in the same condition, poly (Congo red) MCPE for UA shows significantly enhanced peak current corresponding oxidation peak potential was located at $352 \mathrm{mV}$. It is certified that poly (Congo red) MCPE shows very good sensor activity for UA.

\section{DA and UA electrochemical determination by simultaneous method}

Figure 8 depicts the cyclic voltammograms obtained from the mixture containing $0.1 \mathrm{mM}$ DA and $0.1 \mathrm{mM} \mathrm{UA}$ at $\mathrm{pH}$ 7.0 PBS with the sweep rate $100 \mathrm{mV} / \mathrm{s}$. In bare carbon paste electrode (dashed line) DA and UA shows poor current response, the oxidation peak potential located at 198 and $353 \mathrm{mV}$. In poly (Congo red) MCPE (solid line) exhibits huge enhancement in the peak current of the binary mixture when compared to bare carbon paste electrode. The obtained DA and UA oxidation peak potential were observed at 173 and $324 \mathrm{mV}$ respectively. The peak to peak separation was $151 \mathrm{mV}$. This potential difference was enough to recognize DA and UA at poly (Congo red) MCPE.

\section{Interference study}

The interference investigation was done by DPV technique and the binary mixture of sample contains $0.1 \mathrm{mM}$ DA and $0.1 \mathrm{mM}$ $\mathrm{UA}$ in $0.2 \mathrm{M}$ PBS of $\mathrm{pH}$ 7.0. In which, the concentration of DA

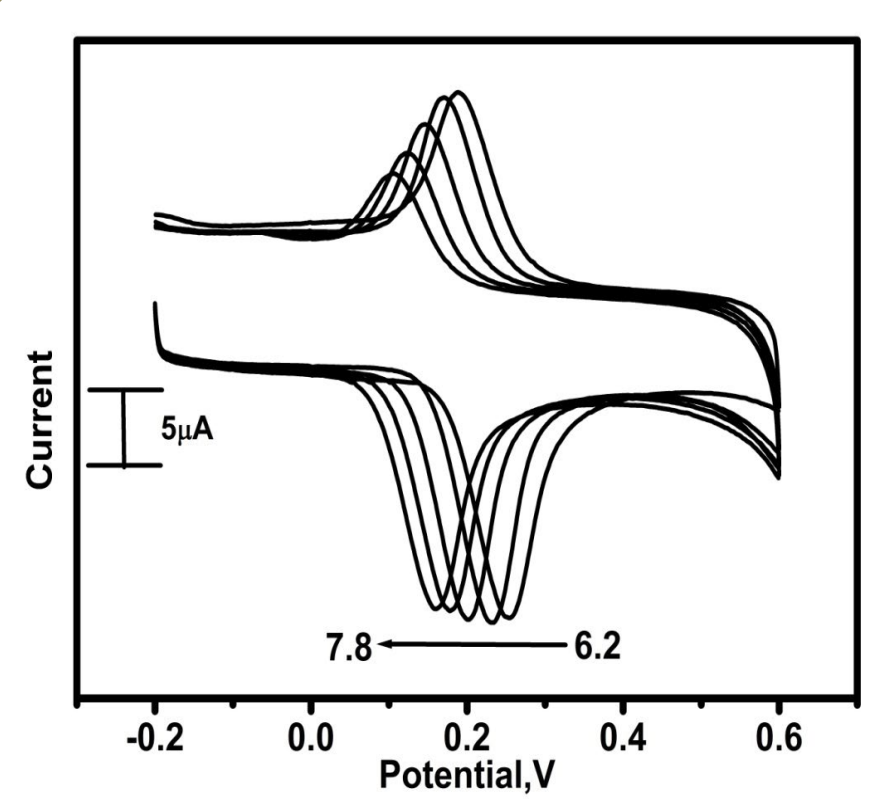

Figure 6a

Cyclic voltammograms of different $\mathrm{pH}$ (a-e: 6.2 to 7.8 ) of poly (Congo red) MCPE.

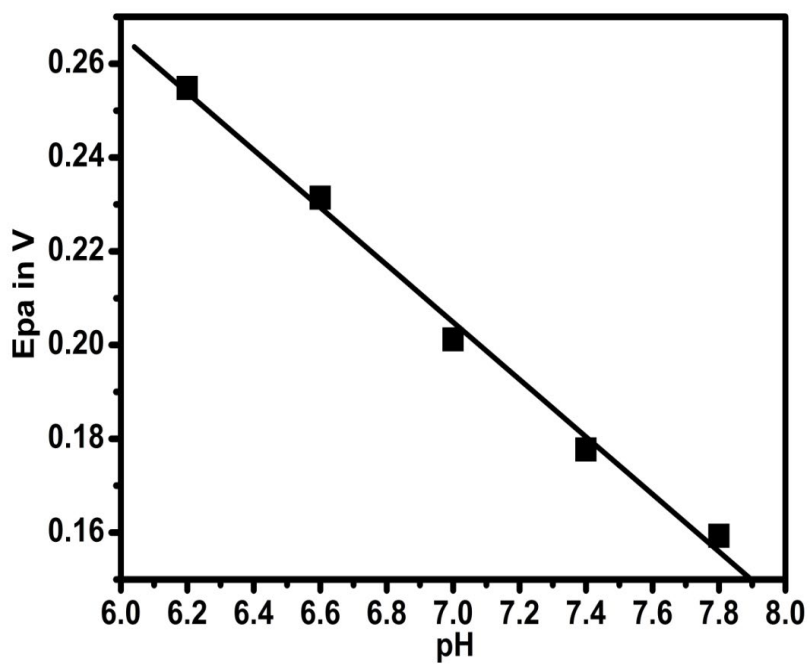

Figure $6 \mathbf{b}$ The graph of anodic peak potential versus different $\mathrm{pH}$ of DA.

was varied from 0.1 to $0.9 \mathrm{mM}$, while keeping the concentration of UA was constant (Figure 9). The obtained voltammogram shows current will be linearly increased with the increase in 


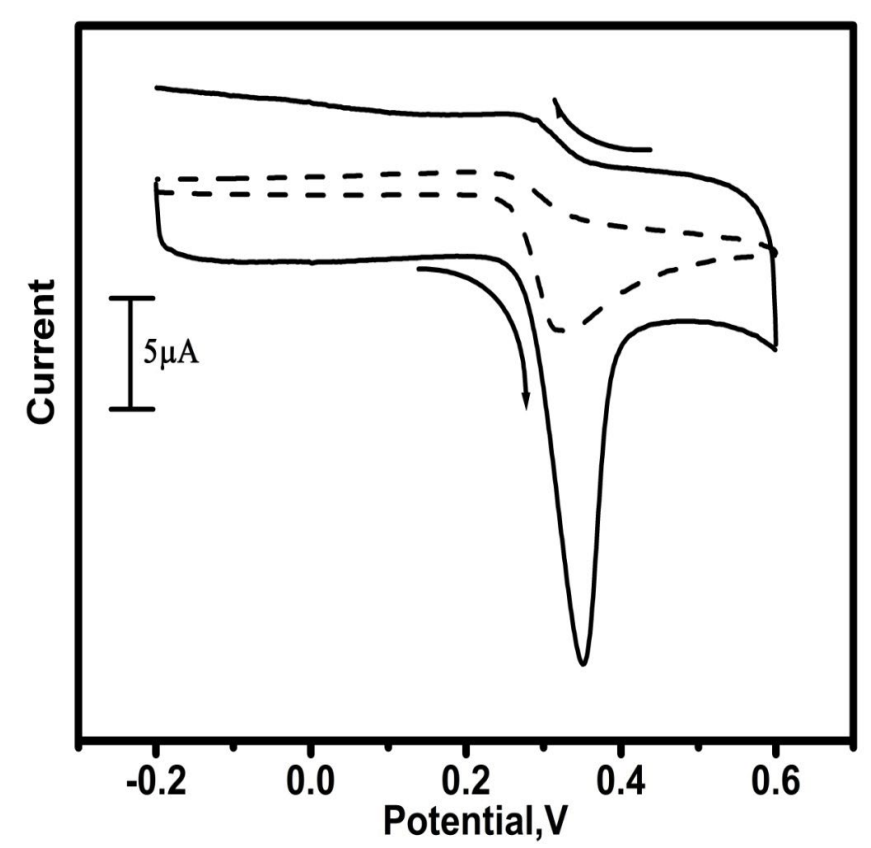

Figure 7 Cyclic voltammograms of $0.1 \mathrm{mM}$ UA in $0.2 \mathrm{M}$ PBS solution of pH 7.0 at BCPE (dashed line) and poly (Congo red) MCPE (Solid line) at the sweep rate of $100 \mathrm{mV} / \mathrm{s}$.

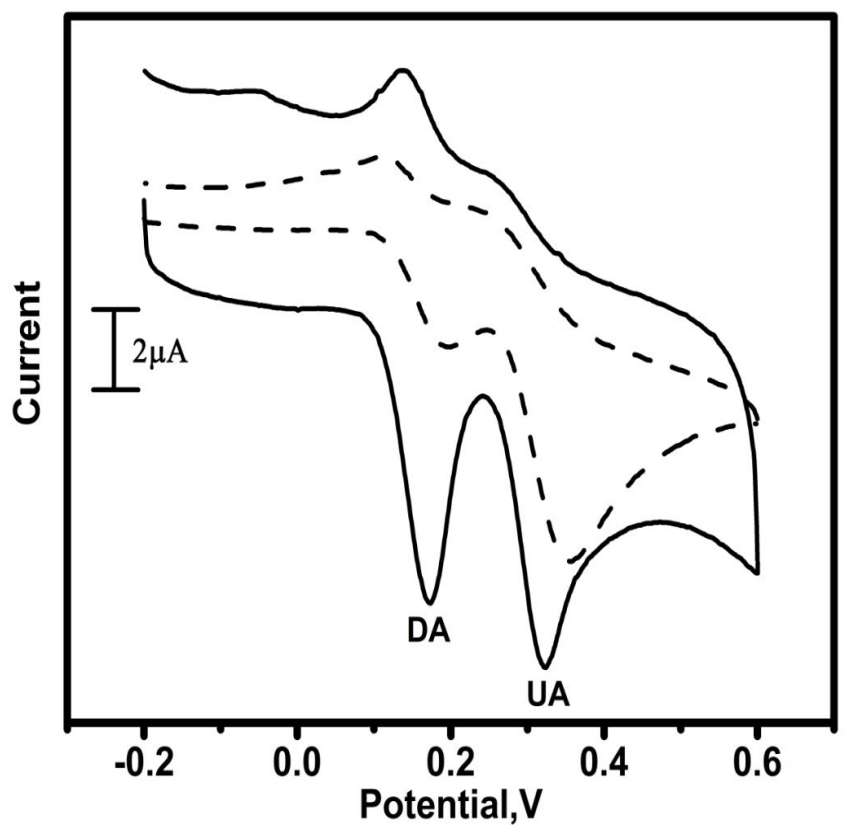

Figure 8

Simultaneous determination for $0.1 \mathrm{mM}$ DA and 0.1 $\mathrm{mM} \cup A$ at BCPE (dashed line) and poly (Congo red) MCPE (solid line) at sweep rate of $100 \mathrm{mV} / \mathrm{s}$.

concentration and no shift in the peak potential of UA. Similarly, by varying the concentration of UA (0.1 to $0.9 \mathrm{mM}$ ) only peak current of UA increased but no change in the peak potential of DA (Figure 10). From the above result, the developed electrode shows the oxidation of DA and UA were independent of each other at poly (Congo red) MCPE

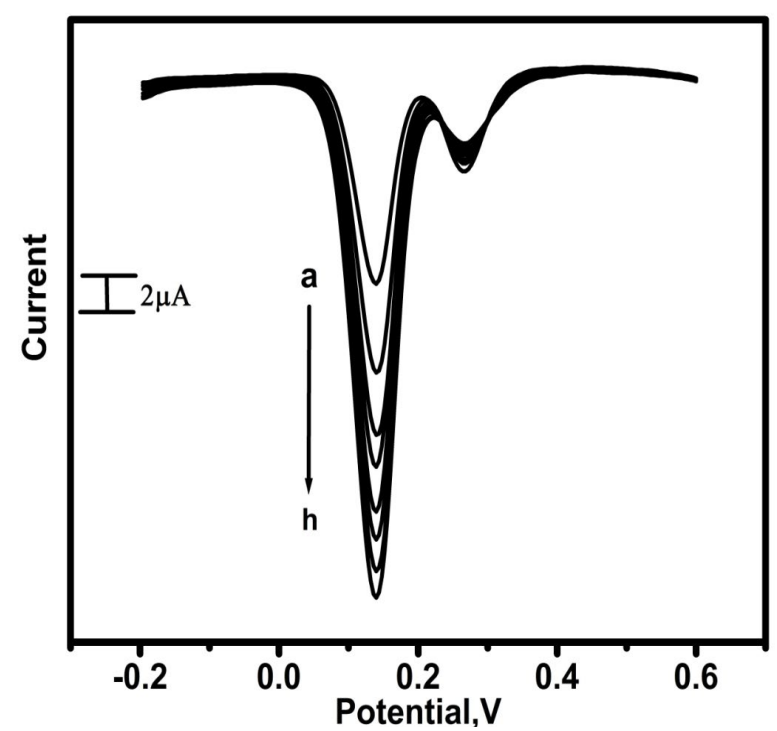

Figure 9 Differential pulse voltammograms (a) $0.1 \mathrm{mM}$ (b) 0.2 $\mathrm{mM}$, (c) $0.3 \mathrm{mM}$, (d) $0.4 \mathrm{mM}$, (e) $0.5 \mathrm{mM}$ (f) $0.6 \mathrm{mM}$ (g) $0.7 \mathrm{mM}$ and(h) $0.8 \mathrm{mM}$ DA in $0.2 \mathrm{M}$ PBS of pH 7.0 in the presence of $0.2 \mathrm{mM} \cup A$ at poly (Congo red) MCPE.

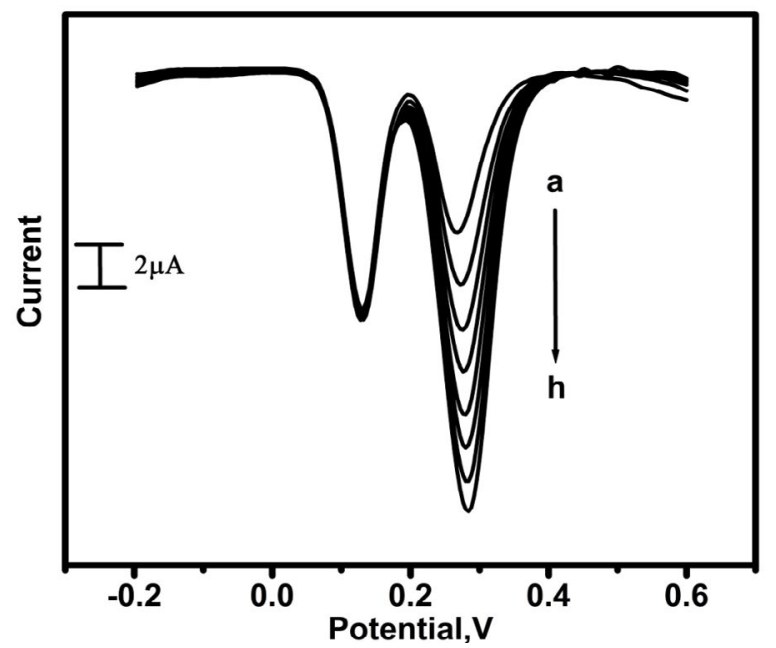

Figure 10 Differential pulse voltammograms of (a) $0.1 \mathrm{mM}$ (b) $0.2 \mathrm{mM}$, (c) $0.3 \mathrm{mM}$, (d) $0.4 \mathrm{mM}$, (e) $0.5 \mathrm{mM}$ (f) 0.6 $\mathrm{mM}(\mathrm{g}) 0.7 \mathrm{mM}$ and(h) $0.8 \mathrm{mM}$ UA in $0.2 \mathrm{M}$ PBS of $\mathrm{pH} 7.0$ in the presence of $0.2 \mathrm{mM}$ DA at poly (Congo red) MCPE.

\section{Conclusion}

Congo red has been directly electropolymerized on the carbon paste electrode surface by CV method. The prepared poly (Congo red) MCPE shown good electrocatalytic activity towards the oxidation of DA and UA and also shows the significant increment in the oxidation of DA and UA individually and simultaneously. The $\mathrm{pH}$ effect indicates the participation of equal number of protons and electrons in the catalytic oxidation. The modified electrode was very suitable and effective for simultaneous determination 
of DA and UA was possible at poly (Congo red) MCPE with peak to peak separation of $151 \mathrm{mV}$ by CV techniques. Over all the poly (Congo red) MCPE shows stability, selectivity, sensitivity, reproducibility for the determination of neurotransmitter. It is expected that with its high electrocatalytic behaviour the poly (Congo red) MCPE could hold great application in the fields of electro analytical chemistry and biosensors. 


\section{References}

1 Munoz AJ, Wanichthanarak K, Meza E, Petranovic D (2012) Systems biology of yeast cell death. FEMS Yeast Res 12: 249-265.

2 Berman SB, Hastings TG (1999) Dopamine oxidation alters mitochondrial respiration and induces permeability transition in brain mitochondria: implications for Parkinson's disease. J Neurochem 73: 1127-1137.

3 Nagy PI, Alagona G, Ghio C (1999) Theoretical Studies on the Conformation of Protonated Dopamine in the Gas Phase and in Aqueous Solution. J Am Chem Soc 121: 4804-4815.

4 Rifat Emrah Ö, Akhtar H, Silvana A (2014) Recent Developments in Electrochemical Sensors for the Detection of Neurotransmitters for Applications in Biomedicine. Analytical Lett 48: 1044-1069.

5 Venton BJ, Wightman RM (2003) Psychoanalytical Electrochemistry: Dopamine and Behavior. Correlating neurochemical changes in the brain with behavior marks the beginning of an exciting new interdisciplinary field, psychoanalytical chemistry. Analytical Chem 75: 414A-421A.

6 Wightman RM, May LJ, Michael AC (1988) Detection of dopamine dynamics in the brain. Analytical Chem 60: 769A-779A.

7 Sulzer D, Zecca L (2000) Intraneuronal dopamine-quinone synthesis: a review. Neurotox Res 1: 181-195.

8 Veera Manohara Reddy Y, Prabhakara Rao V, Vijaya Bhaskar Reddy A, Lavanya M, Venu M, et al. (2015) Determination of dopamine in presence of ascorbic acid and uric acid using poly (Spands Reagent) modified carbon paste electrode. Materials Sci Eng C 57: 378-386.

9 Arslan F (2008) An Amperometric Biosensor for Uric Acid Determination Prepared from Uricase Immobilized in PolyanilinePolypyrrole Film. Sensors 8: 5492-5500.

10 Zen JM, Tang JS (1995) Square-Wave Voltammetric Determination of Uric Acid by Catalytic Oxidation at a Perfluorosulfonated Ionomer/ Ruthenium Oxide Pyrochlore Chemically Modified Electrode. Analytical Chemistry 67: 1892-1895.

11 Alderman MH (2002) Uric Acid and Cardiovascular Risk. Current Opinion in Pharmacology 2: 126-130.

12 Rodman JS, Williams JJ, Peterson CM (1984) Dissolution of Uric Acid Calculi. Journal of Urology 131: 1039-1044.

13 Raj CR, Ohsaka T (2003) Voltammetric Detection of Uric Acid in the Presence of Ascorbic Acid at a Gold Electrode Modified with a SelfAssembled Monolayer of Hetero aromaticthiol. J Electroanalytical Chem 540: 69-77.

14 Wring SA, Hart JP (1992) Chemically Modified, Carbon-Based Electrodes and Their Application as Electrochemical Sensors for the Analysis of Biologically Important Compounds. Analyst 117: 1215-1229.

15 Miland E, Ordieres AJM, BInaco PT, Smyth MR, Fagian CO (1996) Poly (oaminophenol)-modified bienzyme carbon paste electrode for the detection of uric acid. Talanta 43: 785-796.

16 Ganesh PS, Kumara Swamy BE (2015) Simultaneous electroanalysis of norepinephrine, ascorbic acid and uric acid using poly (glutamic acid) modified carbon paste electrode. Journal of Electroanalytical Chemistry 752: 17-24.

17 O'Neill RD (1994) Microvoltammetric techniques and sensors for monitoring neurochemical dynamics in vivo. A review. Analyst 119: 767-779.
18 Guadalupe AR, Abruna HD (1985) Electroanalysis with chemically modified electrodes. Anal Chem 57: 142-149.

19 Shibahara H, Ando A, Suzuki S, Uematsu N, Nishimura D (2011) Oxycodone and pregabalin using transdermal fentanyl patch provided relief of symptoms for postherpetic neuropathic pain in a patient with non-small cell lung cancer. Gan To Kagaku Ryoho 38 : 1675-1677.

20 Shibahara H, Okubo K, Takeshita N, Nishimura D (2012) Medical treatment including pregabalin and radiation therapy provided remarkable relief for neuropathic pain by brachial plexus invasion in a patient with esophageal cancer. Gan To Kagaku Ryoho 39: 277-280.

21 Tanuja SB, Kumara Swamy BE, Vasantakumar Pai K (2016) Electrochemical Response of Dopamine in Presence of Uric Acid at Pregabalin Modified Carbon Paste Electrode: A Cyclic Voltammetric Study. J Anal Bioanal Tech 7: 1.

22 Ohnuki Y, Ohsaka T, Matsuda H, Oyama N (1983) Permselectivity of films prepared by electrochemical oxidation of phenol and aminoaromatic compounds. J Electroanal Chem 158: 55-67.

23 Volkov A, Tourillon G, Lacaze PC, Dubois JE (1980) Electrochemical polymerization of aromatic amines: IR, XPS and PMT study of thin film formation on a Pt electrode. J Electroanal Chem 115: 279-291.

24 Liqing L, Jinghua C, Hong Y, Yuanzhong C, Yanjie Z, et al. (2008) Simultaneous determination of dopamine, ascorbic acid and uric acid at poly (Evans Blue) modified glassy carbon electrode. Bioelectrochemistry 73: 11-17.

25 Shahrokhian S, Zare-Mehrjardi RH (2009) Synthesis of Polypyrrole in the Presence of Congo Red; Application to Selective Voltammetric Determination of Dopamine in the Presence of Ascorbic Acid. Electroanalysis 21: 157-164.

26 Zhao Q, Yuan R, Mo CL, Chai YQ, Zhong X (2004) A New Amperometric Glucose Biosensor with Naphthol Green B as Mediator. Chinese Chemical Letters 2: 208-211.

27 Cai CX, Xue KH (1998) Electrochemical characterization of electropolymerized film of Naphthol-green-B and its electrocatalytic activity toward NADH oxidation. Microchem J 58: 197-208.

28 Mohadesi A, Taher MA (2007) Electrochemical behavior of Naphthol green $B$ doped in poly pyrrole film and its application for electrocatalytic oxidation of ascorbic acid. Sens Actuators 123B: 733-739.

29 Chitravathi S, Kumara Swamy BE, Mamatha GP, Sherigara BS (2012) Electrochemical behavior of poly (naphthol green B)-film modified carbon paste electrode and its application for the determination of dopamine and uric acid. J Electroanalytical Chemistry 667: 66-75.

30 Kiranmai S, Veera Manohara Reddy Y, Venu M, Madhuri CH, Anitha $\mathrm{K}$, et al. (2017) Determination of Terazosin by using Poly (Congo red) Modified Carbon Paste Electrode. Anal Bioanal Electrochem 9: 154-163.

31 Gilbert O, Kumara Swamy BE, Chandra U, Sherigara BS (2009) Simultaneous detection of dopamine and ascorbic acid using polyglycine modified carbon paste electrode: A cyclic voltammetric study. J Electroanal Chem 636: 80-85.

32 Chandra U, Kumara Swamy BE, Gilbert O, Sherigara BS (2010) Voltammetric resolution of dopamine in the presence of ascorbic acid and uric acid at poly (calmagite) film coated carbon paste electrode. Electrochimica Acta 55: 7166-7174.

3 Reddy S, Kumara Swamy BE, Jayadevappa H (2012) CuO nanoparticle sensor for the electrochemical determination of dopamine. Electrochem Acta 61: 78-86. 
34 Mahanthesha KR, Kumara Swamy BE, Chandra U, Bodke YD, Vasantakumar P, et al. (2009) Cyclic Voltammetric Investigations of Alizarin at Carbon Paste Electrode using Surfactants. Int J Electrochem Sci 4: 1237-1247.

35 Raoof JB, Kiani A, Ojani R, Valiollahi R (2011) Electrochemical Determination of Dopamine Using Banana-MWCNTs Modified Carbon Paste Electrode. Anal Bioanal Electrochem 3: 59-66.

36 Skeika T, Zuconelli CR, Fujiwara ST, Pessoa CA (2011) Preparation and Electrochemical Characterization of a Carbon Ceramic Electrode Modified with Ferrocenecarboxylic Acid. Sensors 11: 1361-1374.

37 Wang M, Xu X, Gao J (2007) Voltammetric studies of a novel bicopper complex modified glassy carbon electrode for the simultaneous determination of dopamine and ascorbic acid. J Appl Electrochem 37: 705-710.

38 Huang PF, Wang L, Bai JY, Wang HJ, Zhao YQ, et al. (2007) Simultaneous electrochemical detection of dopamine and ascorbic acid at a poly (p-toluene sulfonic acid) modified electrode. Microchim Acta 15: 741-747.

39 Sun W, Yang M, Jiao K (2007) Electrocatalytic oxidation of dopamine at an ionic liquid modified carbon paste electrode and its analytical application. Anal Bioanal Chem 389: 1283-1291.

40 Li NB, Ren W, Luo HQ (2007) Caffeic Acid-Modified Glassy Carbon Electrode for the Simultaneous Determination of Epinephrine and Dopamine. Electroanalysis 19: 1496-1502.

41 Wang Q, Li N, Wang W (2002) Electrocatalytic response of dopamine at a metallothioneins self-assembled gold electrode. Anal Sci 18: 635.

42 Kuskur CM, Kumara Swamy BE, Jayadevappa H (2015) Electrochemical Investigation of Paracetamol at Poly (Glycine) Modified Carbon Paste Electrode: A Voltammetric Study. J Anal Bioanal Tech 6: 4. 